\title{
Effect of CD44st and HER2 expression on the postoperative prognosis of breast cancer patients
}

This article was published in the following Dove Press journal:

OncoTargets and Therapy

\author{
Dan Dan Chen' \\ Jun An Ji \\ Hai Cui Yan' \\ Guan Hong Huang' \\ Xin Jian Fang'
}

'Department of Oncology, The Second People's Hospital of Lianyungang (Lianyungang Hospital affiliated to Bengbu Medical College), Lianyungang, Jiangsu 222000, China; ${ }^{2}$ Department of Medical Oncology, The Gan Yu District Hospital of Lianyungang, Lianyungang, Jiangsu 222000, China
Correspondence: Xin Jian Fang; Guan Hong Huang

Department of Oncology, The Second People's Hospital of Lianyungang

(Lianyungang Hospital affiliated to Bengbu Medical College), No 4I, Hailianeast

Road, Lianyungang, Jiangsu 222000, China

Email lygfxj@I26.com;

hghlyg0002@sina.cn
Objective: CD44st is a member of the CD44 family; abnormal expression of some CD44 isoforms are closely associated with axillary lymph node metastasis, cancer progression, and patients' prognosis. The objective of this study is to investigate the correlation between the expression of CD44st and HER2 in breast cancer and the effect on patients' prognosis.

Methods: Primers were designed to target the CD44st mRNA (Gene Bank No FJ216964) which has been newly identified in a drug-resistant breast cancer cell line. The expression of CD44st and HER2 mRNA and proteins in cancerous and paracancerous tissue of postoperative breast cancer patients was detected and compared. Tissue samples were obtained from 102 cases of invasive ductal carcinoma, 19 cases of intraductal carcinoma, and 11 cases of medullary carcinoma. The correlation between CD44st and HER2 expression and clinical pathological features was examined.

Results: The expression rate of CD44st mRNA and protein in breast cancer tissue was $64.4 \%$ (85/132), while HER 2 mRNA and protein was expressed in $22.0 \%(29 / 106)$ of the samples. The expression of CD44st and HER2 were low in paracancerous tissue. In breast cancer tissue, the expression rate of HER2 mRNA and protein in the CD44st-positive group was $28.2 \%$ (24/85), and $10.6 \%(5 / 47)$ in the CD44st-negative group. This difference was statistically significant $(P=0.015)$. Sequencing analysis showed that the amplified CD44st gene in this study was the same as that which was previously discovered in the drug-resistant breast cancer cell line. A linear correlation was found between the expression of CD44st and HER2 $(r=0.972$, $\left.r^{2}=0.945, F=2,213.51, P<0.001\right)$. The expression of CD44st and HER2 was also closely associated with luminal cancer subtypes, lymph node metastasis, and TNM stage $(P<0.05)$, but not associated with age, pathological type, or tumor size $(P>0.05)$. The median overall survival in the CD44st high-expression group was 51.85 months (95\% CI: 48.48-55.22), which was significantly shorter than that in the CD44st low-expression group (57.61 months; $95 \% \mathrm{CI}$ : 55.54-59.68, $P=0.032$ ).

Conclusion: CD44st is closely related to the expression of HER2. The expression of CD44st affects patient prognosis and is associated with lymph node metastasis, TNM staging, and molecular subtyping.

Keywords: CD44st, HER2, invasion, breast cancer, metastasis, prognosis

\section{Introduction}

CD44, a ligand of hyaluronan, is an important but unclassified adhesion molecule. The CD44 molecule can mediate intracellular cell signaling through its interaction with cytoskeletal proteins. An increasing number of studies have shown that the CD44 molecule is not only a marker of cancer stem cells but is also directly involved in carcinogenesis and tumor progression. ${ }^{1}$ The abnormal expression of some CD44 isoforms can significantly increase the invasion capacities of cancer cells and is closely 
associated with tumors metastasis ${ }^{2,3}$ and patient prognosis. ${ }^{4,5}$ However, research in this field remains controversial. The study showed that low CD44 expression was associated with higher frequency of recurrence, ${ }^{6}$ and high CD44s expression had a trend toward increased disease-free survival (DFS) and disease-related survival, while expression of CD44v6 isoforms did not correlate with clinical outcome. ${ }^{7}$ Therefore, it is necessary to explore the relationship among the expression of CD44 isoforms and the progression and prognosis of breast cancer.

We cloned a novel short-tailed isoform of CD44st from the multidrug-resistant MCF-7/Adr breast cancer cell line (Gene Bank FJ216964). In a previous study, it was found that in MCF-7/CD44st cells, hyaluronic acid (HA) can interact with CD44st and increase the secretion of MMP-2 and MMP-9 through the MAPK pathway. This consequently increased the invasiveness of tumor cells. The CD44st gene is probably also associated with aggressiveness, metastasis, and prognosis of breast cancer. ${ }^{8,9}$ Further studies have suggested that HA can upregulate the expression of HER2 and TGF $\beta$, induce the activation of the AKT pathway and transcription factor AP-1 in MCF-7/CD44st cells, and increase the invasiveness of tumor cells. ${ }^{10}$

Having strong tumor invasion and metastasis ability, and consequently associated with a poor prognosis, patients who are positive for HER2 account for 15\%-20\% of all breast cancer cases. ${ }^{11}$ However, chemotherapy combined with antiHER2 antibody trastuzumab can improve the prognosis of HER2-positive patients in contrast to patients receiving only chemotherapy. ${ }^{12,13}$ Given these observations, it is necessary to clarify the correlation between the expression of CD44st mRNA and the expression of HER2 mRNA in breast cancer tissue, as well as the effect that this expression has on tumor metastasis and patient prognosis.

\section{Materials and methods Experimental materials \\ Patients}

Following radical mastectomy, a total of 132 paraffin-embedded tissue specimens were collected from the Lianyungang Cancer Hospital (Lianyungang Second People's Hospital) between January 2010 and January 2012. These samples included 109 cases of invasive ductal carcinomas and 23 cases of invasive lobular carcinomas. Paracancerous tissue was collected as a negative control $5 \mathrm{~cm}$ from the tumor. The expression of CD44st and HER2 was detected, and the effect of their expression on patient prognosis was analyzed. This study was approved by the hospital ethics committee and was conducted in accordance with the Declaration of Helsinki.
The clinical pathological features of the patients included age, TNM staging, pathological type, tumor size, lymph node metastasis, and molecular subtyping (Table 1). All cases were newly diagnosed and did not receive local radiotherapy or systemic chemotherapy. Pathological classification was based on WHO criteria. Postoperative pathological staging was conducted according to criteria presented in the American Joint Committee on Cancer (6th edition), and according to criteria presented in the National Comprehensive Cancer Network Guideline; follow-up was performed every 3-6 months for the first 5 years, and once a year thereafter. Changes in patient condition were recorded. Three cases died

Table I Correlations between the expression levels of CD44st and HER2 mRNAs in breast cancer tissues and the clinicopathological features of patients

\begin{tabular}{|c|c|c|c|}
\hline \multirow[t]{2}{*}{ Variables } & & \multicolumn{2}{|l|}{ Mean \pm SD } \\
\hline & & CD44st & HER2 \\
\hline \multicolumn{4}{|l|}{ Age (years) } \\
\hline$<60$ & & $9.72 \pm 1.24$ & $7.91 \pm 1.03$ \\
\hline \multirow[t]{2}{*}{$\geq 60$} & & $7.84 \pm 1.06$ & $8.56 \pm 0.96$ \\
\hline & $P$-value & 0.124 & 0.469 \\
\hline \multicolumn{4}{|l|}{ TNM stage } \\
\hline I-II & & $11.36 \pm 2.01$ & $12.81 \pm 1.69$ \\
\hline \multirow[t]{2}{*}{ III } & & $7.11 \pm 1.28$ & $6.46 \pm 1.01$ \\
\hline & $P$-value & 0.037 & 0.004 \\
\hline \multicolumn{4}{|l|}{ Pathological patterns } \\
\hline Infiltrating ductal carcinoma & & $10.01 \pm 1.81$ & $11.23 \pm 2.56$ \\
\hline Infiltrating lobular carcinoma & & $8.55 \pm 1.35$ & $8.62 \pm 1.20$ \\
\hline \multirow[t]{2}{*}{ Medullary carcinoma } & & $8.22 \pm 1.89$ & $8.30 \pm 1.22$ \\
\hline & $P$-value & $0.44 I$ & 0.167 \\
\hline \multicolumn{4}{|l|}{ Tumor diameter } \\
\hline TI-T2 & & $9.59 \pm 2.10$ & $11.21 \pm 1.33$ \\
\hline \multirow[t]{2}{*}{ T3 } & & $8.70 \pm 1.20$ & $8.11 \pm 1.63$ \\
\hline & $P$-value & 0.559 & 0.063 \\
\hline \multicolumn{4}{|l|}{ Lymph node metastasis } \\
\hline Yes & & $7.11 \pm 1.23$ & $7.5 \mathrm{I} \pm 1.34$ \\
\hline \multirow[t]{2}{*}{ No } & & $11.88 \pm 1.36$ & $12.01 \pm 1.50$ \\
\hline & $P$-value & 0.011 & 0.018 \\
\hline \multicolumn{4}{|l|}{ Molecular subtype } \\
\hline Luminal $\mathrm{A}$ & & $11.23 \pm 1.56$ & $10.69 \pm 2.05$ \\
\hline Luminal B & & $10.59 \pm 10.66$ & $9.33 \pm 1.96$ \\
\hline HER2 & & $7.83 \pm 1.06$ & $5.6 \mathrm{I} \pm 1.04$ \\
\hline Basal-like & & $7.35 \pm 1.22$ & $12.01 \pm 1.53$ \\
\hline Between groups & $P$-value & 0.023 & 0.009 \\
\hline
\end{tabular}

Notes: Expression of CD44st mRNA: Luminal A vs Luminal B, $P=0.594$; Luminal A vs HER2, $P=0.01$ 9; Luminal $A$ vs Basal-like, $P=0.01$ I; Luminal $B$ vs HER2, $P=0.044$; Luminal $B$ vs Basal-like, $P=0.025$; HER2 vs Basal-like, $P=0.719$. Expression of HER2 mRNA: Luminal $A$ vs Luminal $B, P=0.354$; Luminal $A$ vs HER2, $P=0.006$; Luminal $A$ vs Basal-like, $P=0.368$; Luminal $B$ vs HER2, $P=0.027$; Luminal $B$ vs Basal-like, $P=0.089$; HER2 vs Basal-like $P=0.002$. 
of reasons unrelated to cancer or were lost to follow-up, but were still included in the study as censored data.

\section{Main reagents}

Reverse transcription polymerase chain reaction (RT-PCR) kits, Trizol, paraffin-embedded tissue RNA extraction kits (k1560-2), and reverse transcription cDNA synthesis kits (K1622) were purchased from Thermo Fisher Scientific, Inc. (Waltham, MA, USA). High fidelity Taq enzyme, Taq DNA polymerase (RR066B), and fluorescence quantitative PCR kits (RR066B) were purchased from TaKaRa Bio, Inc. (Mountain View, CA, USA). HER2 (2242) and mouse anti-human CD44 monoclonal antibodies (14-0441) were purchased from Affymetrix, Inc (Santa Clara, CA, USA), while the quantitative real-time PCR instrument was purchased from ABI Corporation (Foster City, CA, USA).

\section{Experimental methods}

RNA extraction from paraffin-embedded tissue, semi-quantitative RT-PCR, and gene sequencing

RNA was extracted from paraffin-embedded tissue using the k1560-2 kit according to the manufacturer's instructions. The conditions for cDNA synthesis were $42^{\circ} \mathrm{C}$ for 60 minutes, and $94^{\circ} \mathrm{C}$ for 5 minutes for 30 cycles. PCR amplification conditions were $94^{\circ} \mathrm{C}$ for 60 seconds, $54^{\circ} \mathrm{C}$ for 30 seconds, $72^{\circ} \mathrm{C}$ for 60 seconds, and $72^{\circ} \mathrm{C}$ for 10 minutes to terminate the reaction. Gene sequencing was performed according to the previously described methods. ${ }^{8}$

\section{Quantitative real-time PCR (qRT-PCR) of CD44st and HER2}

CD44st, HER2, and $\beta$-actin primers for quantitative fluorescence PCR are shown in Table 2. Reaction system: $32.0 \mu \mathrm{L}$ $\mathrm{ddH}_{2} \mathrm{O}, 1.0 \mu \mathrm{L}$ dNTP, $5.0 \mu \mathrm{L} 10 \times$ buffer, $4.0 \mu \mathrm{L} \mathrm{MgCl}_{2}$ (25 mM), $2.0 \mu \mathrm{L}$ of each of the upstream and downstream primers $(10 \mathrm{pM}), 2.0 \mu \mathrm{L}$ Taq DNA polymerase $(5 \mathrm{U} / \mu \mathrm{L})$, and $2.0 \mu \mathrm{L}$ cDNA template. The total reaction volume was $50 \mu \mathrm{L}$. Reaction conditions included 45 cycles of predenaturation at $95^{\circ} \mathrm{C}$ for 30 seconds, $95^{\circ} \mathrm{C}$ for 5 seconds, and $60^{\circ} \mathrm{C}$ for 1 minute. Each sample was run in triplicate, while $\beta$-actin acted as an internal reference. The qRT-PCR reaction system in this study was stable and reproducible, and no nonspecific amplification was observed. In order to obtain the relative expression of the target genes to the reference $\beta$-actin gene, the $\Delta \mathrm{Ct}$ value in the tumor tissue was calculated as $\mathrm{Ct}_{\text {target gene }}-\mathrm{Ct}_{\beta \text {-action }}$.

\section{Immunohistochemical assay}

The immunohistochemical assay was performed according to the manufacturer's instructions (SA2001; Zemai Biotech, Shanghai, China). Four high-power fields with 100 tumor cells/high-power field were randomly selected from each slide. Positive cells were summed and divided by 400 to obtain the positive rate for tumor cells. In scaling results, $1,2,3$, or 4 points were awarded when positive cells were identified in $<25 \%, 26 \%-50 \%, 51 \%-75 \%$, and at least $76 \%$ of the slides, respectively. According to the intensity of staining, a yellow color was awarded 1 point, brown-yellow was scored as 2 points, and brown was given 3 points. Taking the sum of the positive rate and staining intensity, a total score of 1-2 was “-”, 3 was “+”, 4-5 was “++”, and 6-7 was “+++" ( $\leq 3$ points was considered to be negative, while $>3$ points was considered positive).

\section{Statistical analyses}

Statistical analyses were performed using SPSS 16.0 software (SPSS Inc., Chicago, IL, USA). Continuous data were expressed as mean $\pm \mathrm{SD}(\mathrm{x} \pm \mathrm{s})$. The chi-squared test was used to compare the ratios between the two groups. A Kolmogorov-Smirnov test (K-S) test showed that CD44st and HER2 mRNA were 0.13 and 0.18 , respectively, suggesting that the data were normally distributed. Spearman correlation was used to evaluate the correlation between CD44 protein expression and the average $\Delta \mathrm{Ct}$ of CD44st mRNA. Uni and multifactorial analysis methods were all used to analyze the clinical pathological features which include age, TNM staging, pathological type, tumor size, lymph node metastasis, and molecular subtyping. The correlation between CD44st

Table 2 PCR primer sequences

\begin{tabular}{|c|c|c|c|}
\hline Genes & Primer & Sequences & Gene products (bp) \\
\hline \multirow[t]{2}{*}{ CD44st } & Forward primer & 5'-CCCTGCTACCAGACACTCA-3' & 281 \\
\hline & Reverse primer & 5'-TGTTCACCAAATGCACCAT-3' & \\
\hline \multirow[t]{2}{*}{ HER2 } & Forward primer & 5'-CTGGTGACACAGCTTATGCCCT-3' & 113 \\
\hline & Reverse primer & 5'-ATCCCCTTGGCAATCTGCA-3' & \\
\hline \multirow[t]{2}{*}{$\beta$-actin } & Forward primer & 5'-CTCGCGCTACTCTCTCTTTC-3' & 330 \\
\hline & Reverse primer & 5'-CATGTCTCGATCCCACTTAAC-3' & \\
\hline
\end{tabular}


and HER2 mRNA expression was investigated using linear correlation analysis. The Kaplan-Meier method was used for survival analysis. Death due to reasons unrelated to cancer and those lost to follow-up were treated as censored data. A $P<0.05$ was considered to indicate statistical significance.

\section{Results}

\section{Expression of CD44st and HER2 mRNA and protein in breast cancer}

Expression of mRNA and protein for the CD44st and HER2 genes were not observed in any paracancerous tissue. In cancer tissue from 132 patients, there were 85 (64.4\%) patients who were positive for both CD44st mRNA and CD44 protein, and $47(35.6 \%)$ patients who were negative for both. In terms of HER2 expression, 29 (22.0\%) patients showed positivity for both HER2 mRNA and protein, while $103(78.0 \%)$ patients were negative for both mRNA and protein. Subgroup analysis showed, among 85 patients with positive CD44, 24 (28.2\%) patients also had positive HER2 expression, while 61 (71.8\%) patients were HER2 negative. Among 47 patients with negative CD44st, 5 (10.6\%) patients had positive HER2 expression and 42 (89.4\%) were HER2 negative. The positive expression rates of HER2 in CD44-positive and CD44-negative groups were significantly different ( $P=0.015$, Table 3, Figures 1 and 2$)$.

\section{Expression of CD44st mRNA and CD44 protein in breast cancer tissue}

The expression of CD44 protein in tissue samples was detected by immunohistochemical assays, with the score ranging between 2 and 7. The expression of CD44st mRNA was measured by average $\mathrm{Ct}$ value. Spearman correlation analysis was used to evaluate the relationship between CD44 protein and mRNA expression. Results showed that the average $\mathrm{Ct}$ value of CD44st mRNA was closely correlated with CD44 protein $(r=0.811, P=0.011)$.

\section{Correlation between CD44st and HER2} mRNA expression in breast cancer tissue After normalization with internal reference genes, the median Ct value of CD44st and HER2 mRNA in breast cancer tissue

Table 3 Expression of CD44st mRNA as well as CD44 and HER2 mRNA protein in the tissues of 132 patients with breast cancer (\%)

\begin{tabular}{|l|l|l|l|}
\hline Group & N & HER2+ & HER2- \\
\hline CD44 positive & 85 & $24(28.2)$ & $6 I(7 I .8)$ \\
\hline CD44 negative & 47 & $5(10.6)$ & $42(89.4)$ \\
\hline
\end{tabular}

Note: $P=0.015$, Spearman correlation, $r=0.204$.

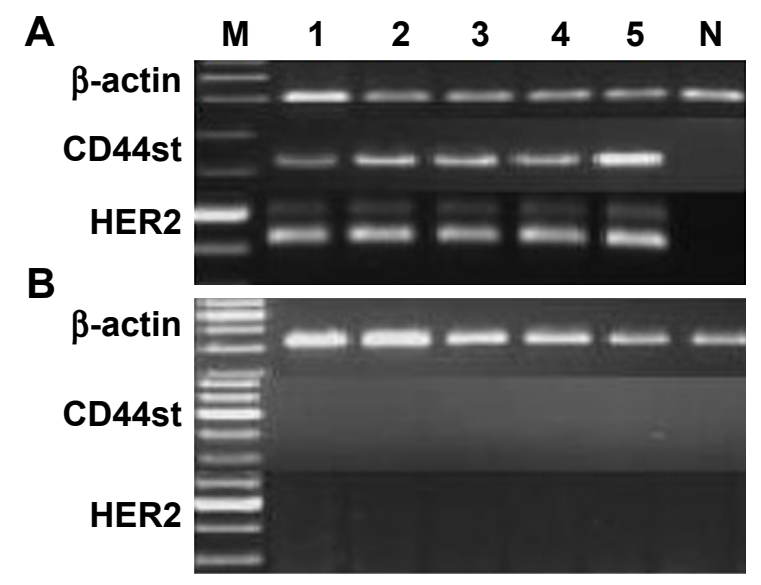

Figure I Expression of CD44st and HER2 in breast cancer tissues.

Notes: Tissue specimen from five different patients (I-5); $\mathrm{N}$ - blank control. (A) Cancer tissues; (B) pericarcinoma tissues.

Abbreviation: $M$, marker.

was 8.91 and 9.39, respectively. Correlation analysis showed that the mRNA expression of CD44st and HER2 was linearly correlated $\left(r=0.972, R^{2}=0.945, F=2,213.5, P<0.001\right.$, Figure 3).

\section{The relationship between CD44st and HER2 mRNA expression and clinicopathological features}

The expression of CD44st and HER2 mRNA was closely associated with tumor TNM stage, lymph node metastasis, and molecular subtyping. The differences in expression were statistically significant $(P<0.05)$. There was no significant association between the expression of CD44st and HER2 mRNA and age, pathological type, and tumor size $(P>0.05$, Table 1). This conclusion was also confirmed by multivariate logistic regression analysis when HER 2 mRNA was set as the dependent variable and the $\Delta \mathrm{Ct}$ value of the expression of CD44st was examined (CD44st, $R^{2}=0.826$; HER2, $R^{2}=0.853$, $P<0.05)$.

\section{Effect of CD44st and HER2 expression on disease-free and OS}

A receiver operating characteristic curve was used to evaluate the significance of CD44st and HER2 expression in predicting patient prognosis. The corresponding Youden index was the best cutoff value. The best cutoff $\mathrm{Ct}$ values of CD44st and HER2 mRNA were 9.11 and 9.69, respectively. The median DFS in the CD44st high-mRNA expression group was 46.89 months (95\% CI: 42.81-50.97 months), while the median DFS in the CD44st low-expression group was 53.34 months (95\% CI: 49.80-56.88 months, $P=0.037$; Figure 4). The median OS in the CD44st high-mRNA expression group was 51.85 months (95\% CI: 48.48-55.22 months), 

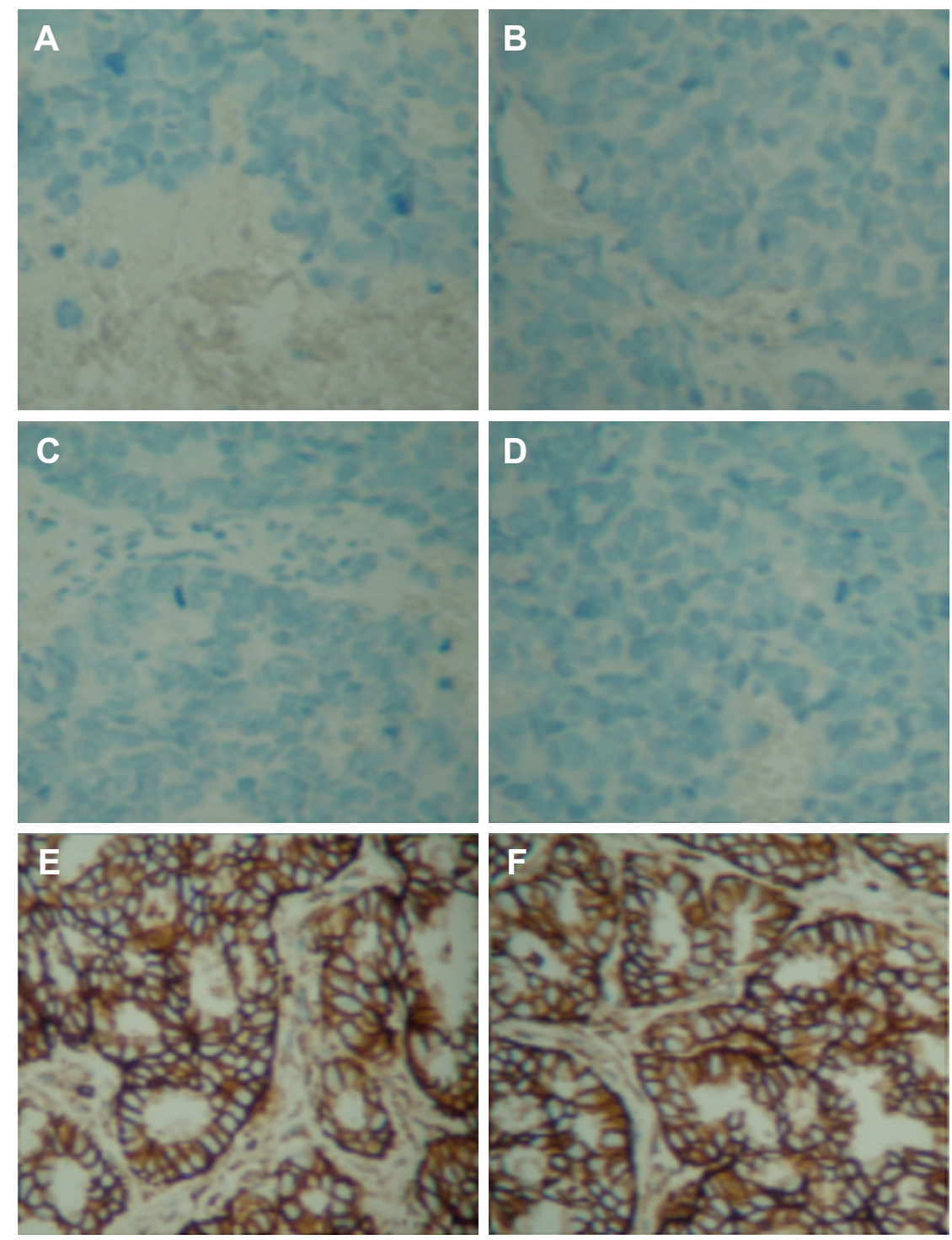

Figure 2 Expression of the CD44 and HER2 proteins in breast cancer tissues detected by using immunohistochemistry method.

Notes: (A) CD44-negative tissue from breast cancer (blank control ×400); (B) HER2-negative tissue from breast cancer (blank control $\times 400$ ); (C) CD44-negative tissue from breast cancer (negative control X400); (D) HER2-negative tissue from breast cancer (negative control ×400); (E) CD44-positive tissue from breast cancer; (F) HER2positive tissue from breast cancer.

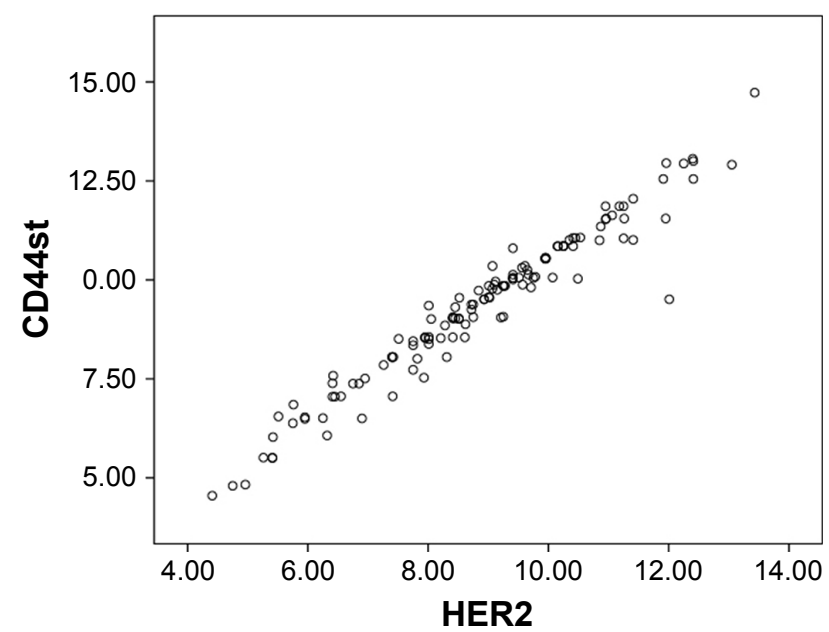

Figure 3 Expression of CD44st and HER2 mRNAs in breast cancer tissues. while the median OS in CD44st low-expression group was 57.61 months (95\% CI: 55.54-59.68 months, $P=0.032$; Figure 5). The median DFS in the HER2 high-mRNA expression group was 47.65 months (95\% CI: 43.34-51.95 months), and 56.63 months (95\% CI: 54.16-59.11 months) in the low-expression group $(P=0.002$; Figure 6$)$. The median OS in HER2 high- and low-mRNA expression groups was 48.42 months (95\% CI: 44.36-52.49 months) and 57.56 months (95\% CI: 55.46-59.66 months), respectively $(P<0.001$; Figure 7$)$.

\section{Discussion}

Our study confirms that CD44st and HER2 mRNA are highly expressed in breast cancer but not adjacent tissue, and that 


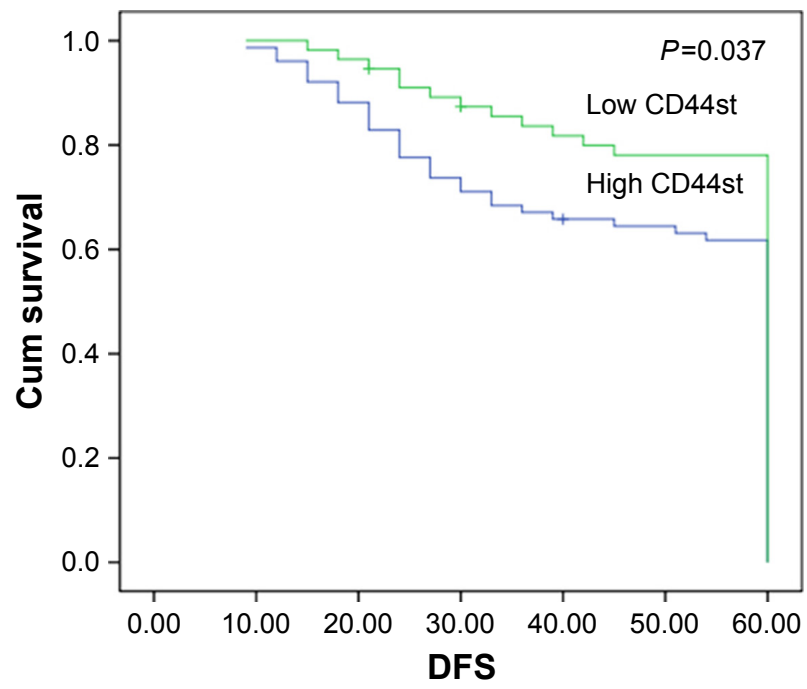

Figure 4 DFS of patients with breast cancer tissues were stratified by CD44st mRNA expression.

Abbreviation: DFS, disease-free survival.

CD44st and HER2 mRNA expression is linearly correlated. CD44st expression is significantly higher in Luminal A and Luminal B cancer subtypes than in HER2-positive and basal cell cancer subtypes. For the reason of lacking CD44st-specific monoclonal antibody, CD44 monoclonal antibody and specific CD44st mRNA primer were used for detecting expression of CD44st in the tissue of breast cancer patients. A previous study has also shown that, when compared to HER2-negative patients, the expression of HA in breast cancer cells and the expression of CD44 in tumor stromal cells are significantly increased in HER2-positive

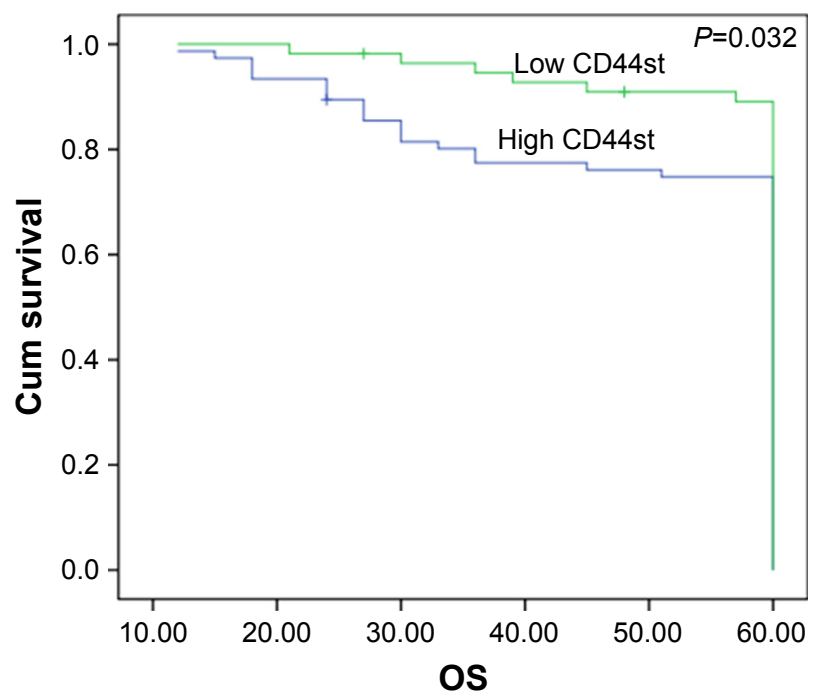

Figure 5 OS of patients with breast cancer tissues were stratified by CD44st mRNA expression.

Abbreviation: OS, overall survival.

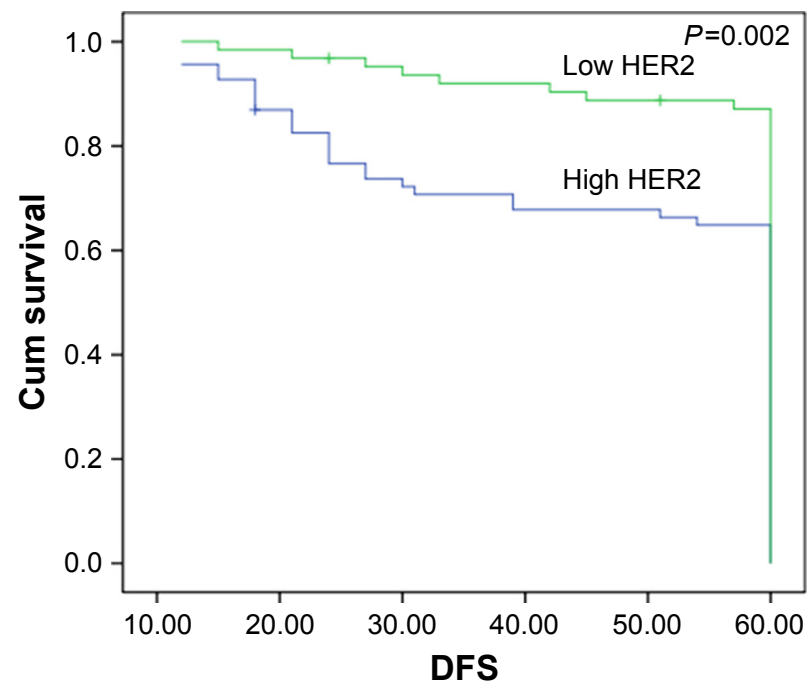

Figure 6 DFS of patients with breast cancer tissues were stratified by HER2 mRNA expression.

Abbreviation: DFS, disease-free survival.

patients. Moreover, positive results for CD44 in stromal cells are closely associated with positive HER2 results in breast cells, estrogen receptor negative, and poor differentiation and patient prognosis. The study suggests that HER2 expression in tumor cells is closely correlated with HA and CD44 expression. ${ }^{14}$

For breast cancer patients, TNM staging is an independent prognostic factor. TNM staging is mainly related to tumor size, lymph node metastasis, and distant metastasis. Our study confirmed the upregulation of CD44st and HER2 in breast cancer tissue and the association of their expression with

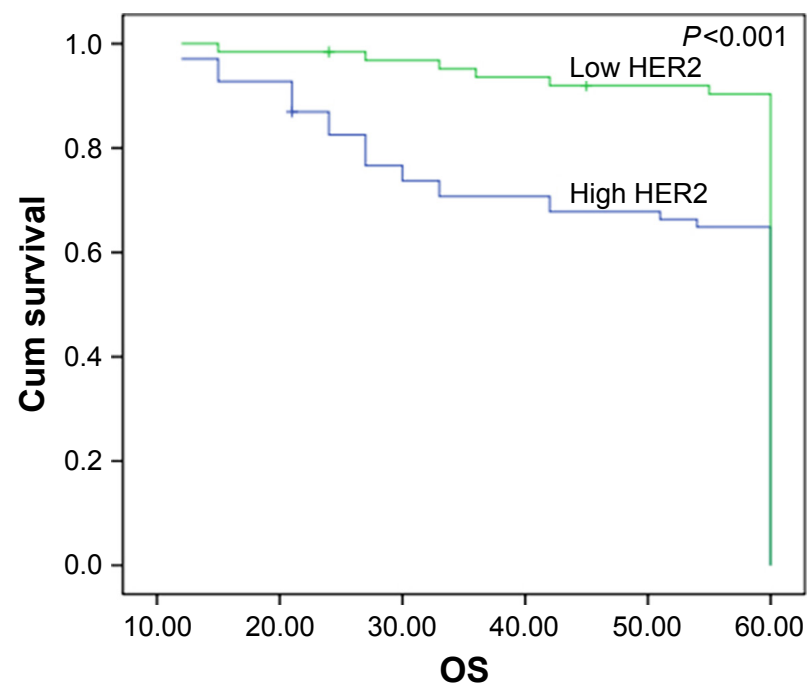

Figure 7 OS of patients with breast cancer tissues were stratified by HER2 mRNA expression.

Abbreviation: OS, overall survival. 
lymph node metastasis, molecular subtyping, and TNM stage. DFS and OS were significantly lower in CD44st and HER2 high-expression groups in comparison to low-expression groups. Patients with high CD44st and HER2 expression were prone to metastasis and relapse, which in turn affected patient prognosis.

Recent studies suggest that the multifunctional CD44 family of proteins are involved in molecular subtyping of breast cancer and play an important role in the development of the cancer. For example, breast cancer expressing CD44v has a better prognosis and is associated with the Luminal $\mathrm{A}$ cancer subtype. CD44s-associated cancer is linked to HER2positive results and basal cell cancer. It is also associated with a worse prognosis. ${ }^{15,16}$ High expression of CD44v2-v10 is associated with estrogen receptor positivity, high levels of differentiation, and Luminal A cancer, while CD44v8-v10 is associated with EGFR positivity, low expression of HER2, and basal cell cancer. ${ }^{16}$ Studies also show that in HER2positive patients, the serum level of CD44 is closely related to survival time and prognosis. For HER2-positive patients, CD44 is both a prognostic biomarker and new therapeutical target. ${ }^{17}$ A recent study found that, in MCF-7 cells, hnRNPM could affect the invasiveness of tumor cells by regulating CD44s. Similarly, in breast cancer tissue, the expression of hnRNPM and CD44s was closely correlated and was also shown to affect lymph node metastasis and prognosis, thereby presenting itself as a potential therapeutic target. ${ }^{18}$

$\mathrm{HA}$ binds to the CD44 isoform which is widely distributed on the cell surface and induces the activation of cytoskeletal proteins, ankyrins, small G protein Rho, and the PI3K-AKT pathway. This leads to the increased adhesion, growth, proliferation, migration, and invasiveness of MCF-7 cells. ${ }^{19}$ In breast cancer, increased CD44 expression is correlated with histological grade, estrogen status, HER2 and EGFR receptor expression, and also affects the prognosis of HER2-positive patients and patients with basal cell cancer. ${ }^{20}$ Furthermore, CD44 expression can cause HER2-positive breast cancer cells to become resistant to the trastuzumab monoclonal antibody, ${ }^{21}$ and is also closely associated with poor prognosis in some patients. ${ }^{22,23}$

In some solid tumors, CD44 is an attractive biomarker for tumor stem cells. The interaction between HA and CD44 activates the EGFR-mediated signaling pathway, which affects tumor cell growth, migration, and drug resistance. Increasing evidence suggests that differences in CD44 isoforms not only affect the transduction of the HA-CD44 signaling pathway but is also related to molecular typing and tumor progression. Current studies suggest that in conjunction with chemo and radiotherapy, the use of monoclonal antibodies against different CD44 isoforms combined with target agents to suppress HA/CD44-mediated signal transduction is a promising strategy for patients with advanced tumors. ${ }^{24}$ Preliminary results in the treatment of lung cancer support this hypothesis. In a phase II clinical trial targeting small cell lung cancer, the combination of HA with irinotecan and carboplatin was well tolerated in CD44spositive patients and advanced patient survival. ${ }^{25}$

However, there are still some disputes concerning the effect of the CD44 family proteins on the prognosis of patients. For breast cancer patients, the $\mathrm{CD} 44^{-} / \mathrm{CD} 24^{+}$phenotype, common in hormone receptor and HER2-positive patients, is negatively correlated with lymph node metastasis, and is associated with a better prognosis than other cancer subtypes. A less severe prognosis is also observed in hormone receptor negative patients expressing CD44. ${ }^{26}$ A metaanalysis including 5,697 breast cancer patients concluded that CD24 overexpression, but not CD44 and CD44+/CD24 phenotypes, is closely related to pathological grade, DFS, and OS. ${ }^{27}$ Therefore, the roles of different CD44 isoforms in tumor progression, prognosis, and treatment require further investigation.

Studies find that the binding of HA to CD44 can regulate the activity of EGFRs. ${ }^{28}$ CD44 and EGFR are coexpressed on the cell membrane and can activate downstream signaling proteins MAPK/ERK and calmodulin kinase II, thereby affecting cell differentiation. ${ }^{29}$ In patients with HER2positive breast cancer, the level of serum CD44 is significantly increased. This suggests that it may be worthwhile to further examine the role of CD44 for its potential to reverse trastuzumab resistance, as well as to serve as a prognostic biomarker. ${ }^{30} \mathrm{~A}$ study by Bellerby et al confirmed that overexpression of CD44 was associated with estrogen resistance and promoted the invasive ability of drug-resistant cells. In estrogen-sensitive MCF-7 cells, overexpression of CD44v6 can enhance the invasiveness of tumor cells and reduce its response to anti-estrogen agents by activating the EGFR signaling pathway. CD44v6 or EGFR-targeted therapy was able to delay or prevent breast cancer resistance. ${ }^{31}$

\section{Conclusion}

CD44st is closely correlated with HER2 expression in breast cancer patients and may have significant effects on lymph node metastasis, TNM staging, molecular subtyping, and patient survival. Our study provides a theoretical basis for 
molecular therapy targeting CD44st and HER2, and also opens a new direction for the in-depth investigation into the role of CD44st and HER2 in tumor stem cells and multidrug resistance.

\section{Ethical approval and consent to participate}

All participants provided written informed consent for their tissue samples to be used in the study. The study was approved and consented by the Ethics Committee of the Second People's Hospital of Lianyungang (Lianyungang Hospital affiliated to Bengbu Medical College), certificate no: 2016-048-01.

\section{Acknowledgments}

This study was funded by "333" Talents Projects of Jiangsu province (project number: BRA 2016299), the Science and Technology Department of Lianyungang (project number: SH1415), the Health and Family Planning Commission of Jiangsu province (project number: H2017040), and "521" Talent Project of Lianyungang. Dan Dan Chen and Ji Jun An are co-first authors for this study.

\section{Author contributions}

DDC contributed to the experimental research. XJF offered the fund to the experiment and contributed to the study design. GHH contributed to data collection of the test and part of experimental research. JAJ contributed to the data analysis. All authors contributed to data analysis, drafting and revising the article, gave final approval of the version to be published, and agree to be accountable for all aspects of the work.

\section{Disclosure}

The authors report no conflicts of interest in this work.

\section{References}

1. Orian-Rousseau V. CD44 acts as a signaling platform controlling tumor progression and metastasis. Front Immunol. 2015;6(6):154.

2. Sun H, Liu T, Zhu D, et al. HnRNPM and CD44s expression affects tumor aggressiveness and predicts poor prognosis in breast cancer with axillary lymph node metastases. Genes Chromosomes Cancer. 2017; 56(8):598-607.

3. Blacking TM, Waterfall M, Argyle DJ. CD44 is associated with proliferation, rather than a specific cancer stem cell population, in cultured canine cancer cells. Vet Immunol Immunopathol. 2011;141(1-2):46-57.

4. Shipitsin M, Campbell LL, Argani P, et al. Molecular definition of breast tumor heterogeneity. Cancer Cell. 2007;11(3):259-273.

5. Looi LM, Cheah PL, Zhao W, Ng MH, Yip CH. CD44 expression and axillary lymph node metastasis in infiltrating ductal carcinoma of the breast. Malays J Pathol. 2006;28(2):83-86.
6. Sanmartín E, Ortiz-Martínez F, Pomares-Navarro E, et al. CD44 induces FOXP3 expression and is related with favorable outcome in breast carcinoma. Virchows Arch. 2017;470:81-90.

7. Diaz LK, Zhou X, Wright ET, et al. CD44 expression is associated with increased survival in node-negative invasive breast carcinoma. Clin Cancer Res. 2005;11(9):3309-3314.

8. Fang XJ, Jiang H, Zhao XP, Jiang WM. The role of a new CD44st in increasing the invasion capability of the human breast cancer cell line MCF-7. BMC Cancer. 2011;11:290.

9. Fang XJ, Jiang H, Zhu YQ, Zhang LY, Fan QH, Tian Y. Doxorubicin induces drug resistance and expression of the novel CD44st via NF-KB in human breast cancer MCF-7 cells. Oncol Rep. 2014;31(6): $2735-2742$

10. Ying Zhi L, Xu Z, Ning L, et al. A correlation study of the expression of HA-CD44st and HER-2 in breast cancer. Onco Targets Ther. 2018;11:5677-5688.

11. Slamon DJ, Clark GM, Wong SG, Levin WJ, Ullrich A, McGuire WL. Human breast cancer: correlation of relapse and survival with amplification of the HER-2/neu oncogene. Science. 1987;235(4785): 177-182.

12. Marty M, Cognetti F, Maraninchi D, et al. Randomized phase II trial of the efficacy and safety of trastuzumab combined with docetaxel in patients with human epidermal growth factor receptor 2-positive metastatic breast cancer administered as first-line treatment: the M77001 study group. J Clin Oncol. 2005;23(19):4265-4274.

13. Papaldo P, Fabi A, Ferretti G, et al. A phase II study on metastatic breast cancer patients treated with weekly vinorelbine with or without trastuzumab according to HER2 expression: changing the natural history of HER2-positive disease. Ann Oncol. 2006;17(4):630-636.

14. Auvinen P, Tammi R, Kosma VM, et al. Increased hyaluronan content and stromal cell CD44 associate with HER2 positivity and poor prognosis in human breast cancer. Int J Cancer. 2013;132(3):531-539.

15. Inoue K, Fry EA. Aberrant splicing of estrogen receptor, HER2, and CD44 genes in breast cancer. Genet Epigenet. 2015;7:19-32.

16. Olsson E, Honeth G, Bendahl PO, et al. CD44 isoforms are heterogeneously expressed in breast cancer and correlate with tumor subtypes and cancer stem cell markers. BMC Cancer. 2011;11:418.

17. Baek JM, Jin Q, Ensor J, Boulbes DR, Esteva FJ. Serum CD44 levels and overall survival in patients with HER2-positive breast cancer. Breast Cancer Res Treat. 2011;130(3):1029-1036.

18. Alamgeer M, Neil Watkins D, Banakh I, et al. A Phase IIa study of HA-irinotecan, formulation of hyaluronic acid and irinotecan targeting CD44 in extensive-stage small cell lung cancer. Invest New Drugs. 2018; 36(2):288-298.

19. Nam K, Oh S, Lee KM, Yoo SA, Shin I. CD44 regulates cell proliferation, migration, and invasion via modulation of c-Src transcription in human breast cancer cells. Cell Signal. 2015;27(9):1882-1894.

20. Xu H, Wu K, Tian Y, et al. CD44 correlates with clinicopathological characteristics and is upregulated by EGFR in breast cancer. Int J Oncol. 2016;49(4):1343-1350.

21. Boulbes DR, Chauhan GB, Jin Q, Bartholomeusz C, Esteva FJ. CD44 expression contributes to trastuzumab resistance in HER2positive breast cancer cells. Breast Cancer Res Treat. 2015;151(3): 501-513.

22. Seo AN, Lee HJ, Kim EJ, et al. Expression of breast cancer stem cell markers as predictors of prognosis and response to trastuzumab in HER2-positive breast cancer. Br J Cancer. 2016;114(10):1109-1116.

23. Qiu Y, Pu T, Guo P, et al. ALDH(+)/CD44(+) cells in breast cancer are associated with worse prognosis and poor clinical outcome. Exp Mol Pathol. 2016;100(1):145-150.

24. Thapa R, Wilson GD. The importance of CD44 as a stem cell biomarker and therapeutic target in cancer. Stem Cells Int. 2016;2016: 2087204.

25. Sun H, Liu T, Zhu D, et al. HnRNPM and CD44s expression affects tumor aggressiveness and predicts poor prognosis in breast cancer with axillary lymph node metastases. Genes Chromosomes Cancer. 2017; 56(8):598-607. 
26. Kim HJ, Kim MJ, Ahn SH, et al. Different prognostic significance of CD24 and CD44 expression in breast cancer according to hormone receptor status. Breast. 2011;20(1):78-85.

27. Wang Z, Wang Q, Wang Q, Wang Y, Chen J. Prognostic significance of CD24 and CD44 in breast cancer: a meta-analysis. Int J Biol Markers. 2017;32(1):75-82.

28. Ghatak S, Misra S, Toole BP. Hyaluronan constitutively regulates ErbB2 phosphorylation and signaling complex formation in carcinoma cells. J Biol Chem. 2005;280(10):8875-8883.

29. Midgley AC, Rogers M, Hallett MB, et al. Transforming growth factor- $\beta 1$ (TGF- $\beta 1$ )-stimulated fibroblast to myofibroblast differentiation is mediated by hyaluronan (HA)-facilitated epidermal growth factor receptor (EGFR) and CD44 co-localization in lipid rafts. J Biol Chem. 2013;288(21):14824-14838.
30. Baek JM, Jin Q, Ensor J, Boulbes DR, Esteva FJ. Serum CD44 levels and overall survival in patients with HER2-positive breast cancer. Breast Cancer Res Treat. 2011;130(3):1029-1036.

31. Bellerby R, Smith C, Kyme S, et al. Overexpression of specific CD44 isoforms is associated with aggressive cell features in acquired endocrine resistance. Front Oncol. 2016;6:145.

\section{Publish your work in this journal}

OncoTargets and Therapy is an international, peer-reviewed, open access journal focusing on the pathological basis of all cancers, potential targets for therapy and treatment protocols employed to improve the management of cancer patients. The journal also focuses on the impact of management programs and new therapeutic agents and protocols on

\section{Dovepress}

patient perspectives such as quality of life, adherence and satisfaction. The manuscript management system is completely online and includes a very quick and fair peer-review system, which is all easy to use. Visit http://www.dovepress.com/testimonials.php to read real quotes from published authors.

Submit your manuscript here: http://www.dovepress.com/oncotargets-and-therapy-journal 